\title{
The South Atlantic dipole and variations in the characteristics of the South American Monsoon in the WCRP-CMIP3 multi-model simulations
}

\author{
Rodrigo J. Bombardi · Leila M. V. Carvalho
}

Received: 19 October 2009/Accepted: 29 April 2010/Published online: 18 May 2010

(C) The Author(s) 2010. This article is published with open access at Springerlink.com

\begin{abstract}
This study investigates relationships between Atlantic sea surface temperature (SST) and the variability of the characteristics of the South American Monsoon System (SAMS), such as the onset dates and total precipitation over central eastern Brazil. The observed onset and total summer monsoon precipitation are estimated for the period 1979-2007. SST patterns are obtained from the Empirical Orthogonal Function. It is shown that variations in SST on interannual timescales over the South Atlantic Ocean play an important role in the total summer monsoon precipitation. Negative (positive) SST anomalies over the topical South Atlantic along with positive (negative) SST anomalies over the extratropical South Atlantic are associated with early (late) onsets and wet (dry) summers over southeastern Brazil and late (early) onset and dry (wet) summers over northeastern Brazil. Simulations from Phase 3 of the World Climate Research Programme Coupled Model Intercomparison Project (CMIP-3) are assessed for the 20th century climate scenario (1971-2000). Most CMIP3 coupled models reproduce the main modes of variability of the South Atlantic Ocean. GFDL2.0 and MIROC-M are the models that best represent the SST variability over the South Atlantic. On the other hand, these models do not succeed in representing the relationship between SST and SAMS variability.
\end{abstract}

R. J. Bombardi $(\bowtie) \cdot$ L. M. V. Carvalho

Department of Geography, University of California,

Ellison Hall, 6813, Santa Barbara, CA 93106-3060, USA

e-mail: bombardi@geog.ucsb.edu

L. M. V. Carvalho

Institute for Computational Earth System Science,

University of California, Santa Barbara, USA
Keywords South American Monsoon .

Sea surface temperature - CMIP3 multi-model dataset . South Atlantic dipole

\section{Introduction}

The South American Monsoon System (SAMS) is characterized by large seasonal variations of convective activity and large-scale circulation over tropical South America (e.g. Zhou and Lau 1998) and has major impacts on agriculture, energy, and water resources management. It has been well documented that the variability of precipitation on interannual timescales over large portions of the tropics and subtropics of South America, which includes regions affected by SAMS, is influenced by the El-Niño-Southern Oscillation (ENSO) (e.g. Ropelewski and Halpert 1987; Grimm et al. 1998; Coelho et al. 2002; Grimm 2003). During ENSO warm phase convection intensifies over western tropical South America with consequent suppression over eastern tropical South America (e.g. Zhou and Lau 2001; Paegle and Mo 2002). Grimm et al. (2007) showed that during the austral spring El Niño events induce subsidence over the Amazon and eastern Brazil, decreasing moisture convergence and precipitation in these regions. In addition, convection over the central and eastern tropical Pacific Ocean associated with ENSO generates wave trains extending poleward and eastward over the Pacific Ocean, consistent with Rossby wave response to anomalous low latitude forcing (Karoly 1989). In the Southern Hemisphere these wave trains show high amplitude over the Southern Pacific and South America and are known as the PacificSouth American teleconnection pattern (PSA-e.g.; Ghil and Mo 1991; Mo 2000). ENSO warm (cold) phases have been associated with increased (decreased) precipitation 
over northeastern Argentina, Uruguay and southern Brazil (Ropelewski and Halpert 1987; Aceituno 1988; Grimm et al. 2000; Coelho et al. 2002; Magaña and Ambrizzi 2005).

Sea surface temperature (SST) variability over the South Atlantic Ocean also plays an important role in South American climate. The dominant mode of atmosphereocean coupled variability over the South Atlantic is a dipole with centers of action over the tropical and extratropical South Atlantic (e.g. Venegas et al. 1997; Sterl and Hazeleger 2003; De Almeida et al. 2007). This dipole pattern is related to the strengthening and weakening of the South Atlantic Subtropical High, which influences lowlevel atmospheric circulation and forces SST fluctuations in a north-south dipole structure (Venegas et al. 1997). Robertson and Mechoso (2000) observed that this SST dipole is associated with the first mode of interannual variability of circulation over South America, characterized by a barotropic equivalent cyclonic flow with a center of action over the western subtropical South Atlantic. Cardoso and Silva Dias (2004) found that temperature over southeastern Brazil is correlated with the south Atlantic SST dipole. Muza et al. (2009) verified that the Atlantic SST dipole pattern is related to extreme precipitation over southeastern Brazil on interannual timescales. They also show that negative SST anomalies over the subtropical South Atlantic and positive SST anomalies over the extratropical South Atlantic are associated with extreme wet events over southeastern Brazil.

Liebmann and Marengo (2001) examined the influence of SST on seasonal precipitation and timing of the rainy season (i.e., variation of start and end dates) over the Amazon. They found that the influence of the SST on seasonal total rainfall is often observed in the timing rather than in the rainy season rain rate. Marengo et al. (2001) observed that negative SST anomalies over the tropical Atlantic Ocean and positive SST anomalies over the tropical Pacific Ocean are related to delays in the onset of the rainy season over the central Amazon whereas positive SST anomalies over the Atlantic Ocean are associated with late demise of the rainy season in the same region.

Taschetto and Wainer (2008a) investigated the influence of subtropical South Atlantic SST anomalies on precipitation in South America in the Community Climate Model (CCM3) from the National Center for Atmospheric Research (NCAR). Their results show that both South Atlantic and Pacific SSTs modulate the intensity and position of the South Atlantic Convergence Zone (SACZ) during the peak of the austral summer (DJF). In these experiments the authors found that the ENSO signal and respective teleconnections seem to influence the intensity of the oceanic portion of the SACZ (Carvalho et al. 2004) by the end of the rainy season (MAM). In the austral spring
(SON) ENSO and subtropical Atlantic SST seem to have the opposite effect upon convection over South America.

The World Climate Research Programme's (WCRP's) Coupled Model Intercomparison Project phase 3 (CMIP3) multi-model dataset consists of climate model outputs from simulations of the past, present and future climate. The WCRP-CMIP3 dataset provides valuable simulations to assess climate change projections. Thus, an evaluation of the skill of these models in reproducing present and past climate is crucial to assess the reliability of their future climate projections.

Previous studies have evaluated the skill of the WCRPCMIP3 models in reproducing the main patterns of SST. Dai (2006) showed large differences between the observed SST over the tropical South Atlantic region and that simulated by the WCRP-CMIP3 models, indicating that most models underestimate SST in this region. AchutaRao and Sperber (2006) verified that in the NINOO3 region, 75\% of the WCRPCMIP3 models succeed in reproducing the spectral maximum of the observed SST, which occurs between 2 and 7 years (e.g. Kestin et al. 1998; AchutaRao and Sperber 2002). In addition, Vera and Silvestre (2009) showed that most WCRP-CMIP3 models are not able to reproduce the PSA pattern, which suggests a low skill of these models in reproducing large scale patterns of precipitation variability on interannual time scales in South America.

Although many studies have documented the impact of ENSO on precipitation over tropical South America, little is known about the influence of the South Atlantic Ocean on the characteristics of SAMS, such as onset and demise dates and accumulated precipitation. Bombardi and Carvalho (2009) evaluated the skill of ten WCRP-CMIP3 models in reproducing SAMS and its variability regarding daily precipitation, mean annual cycle, onset and demise dates, duration, and accumulated precipitation. The purpose of the present study is to evaluate the ability of the same WCRP-CMIP3 models in reproducing the main mode of SST variability over the South Atlantic Ocean and investigate how this mode affects the variability of SAMS. Our focus will be on the onset and demise dates, duration, and total precipitation during the monsoon season. This study is organized as follows: Sect. 2 presents the dataset used in this study. Section 3 examines the spatial and temporal variability of South Atlantic SST from observations and simulations. The relationship between the variability of SST and SAMS are discussed in Sect. 4. Section 5 presents the conclusions.

\section{Data}

Five-day average (pentad) precipitation data were obtained from the Global Precipitation Climatology Project-GPCP 
(Xie et al. 2003) based on gauge and satellite observations (Adler et al. 2003). Muza and Carvalho (2006) verified that GPCP shows a good correspondence with gridded precipitation from stations (Liebmann and Allured 2005) in areas over tropical and subtropical Brazil. Monthly wind at the $850 \mathrm{hPa}$ level and skin temperature were obtained from the NCEP-DOE reanalysis (National Centers for Environmental Prediction-Department of Energy) (Kanamitsu et al. 2002). Skin temperature was used as a proxy for SST. Both NCEP-DOE and GPCP datasets have a resolution of $2.5^{\circ}$ latitude/longitude and extend from 1979 to 2007.

In addition, we examined daily precipitation and monthly skin temperature simulations from ten global coupled climate models for the 20th century climate scenario (20C3M) from 1971 to 2000. These data were obtained from the archives of the World Climate Research Programme's (WCRP's) Coupled Model Intercomparison Project phase 3 (CMIP3) multi-model dataset. Precipitation simulations from the WCRP-CMIP3 models were pentad averaged to compare with GPCP precipitation. All selected models have spatial resolution of at least $2.8^{\circ}$ latitude/ longitude and are composed of atmospheric and oceanic components. None of these models have dynamical vegetation. Table 1 describes the WCRP-CMIP3 models investigated in this study and their characteristics. One simulation from each model is analyzed in this work. A thorough evaluation of the skill of these WCRP-CMIP3 coupled models in simulating SAMS is discussed in Bombardi and Carvalho (2009).

To investigate the influence of SST anomalies on South American precipitation on interannual timescales, monthly $850 \mathrm{hPa}$ wind from NCEP-DOE and skin temperature from both WCRP-CMIP3 and NCEP-DOE datasets were filtered in frequency domain to retain oscillations with periods greater than 12 months (henceforth referred to as SST).

The onset and demise dates of the rainy season, its duration and accumulated precipitation were computed based on the method described in Liebmann and Marengo (2001) and further adapted in Bombardi and Carvalho
(2009). According to this method, the rainy season onset and demise can be estimated based on the behavior of the running sum $(S)$ of the precipitation deviation from the climatological annual mean. $S$ always starts in the dry season for a given grid point. Before the onset of the wet season $S$ is negative and shows negative slope. As rainfall becomes more regular the slope of the running sum begins to increase. $S$ is further smoothed by applying a moving average filter $(\bar{S})$. The onset is defined as the date (pentad) at which the slope of $\bar{S}(d \bar{S} / d t)$ becomes steadily positive. The end of the rainy season is defined when the slope $d \bar{S} / d t$ becomes negative. Once the onset and demise dates are defined, the duration and total monsoonal precipitation can be computed. A comprehensive description of the method as well as the spatial and interannual variability of the onset, demise, duration, and accumulated precipitation during the South America summer monsoon observed with GPCP data and simulated by the same 10 WCRP-CMIP3 coupled models investigated in this study is described in Bombardi and Carvalho (2009).

\section{Atlantic variability in the WCRP-CMIP3 models}

\subsection{South Atlantic variability}

The objective of this analysis is to evaluate the skill of 10 WCRP-CMIP3 models in reproducing the spatial patterns and temporal variation of the main mode of variability of the South Atlantic Ocean. As discussed in the introduction, the first mode of the coupled variability between the atmosphere and the South Atlantic Ocean is known as the South Atlantic Dipole (SAD) (De Almeida 2006). The skill of the WCRP-CMIP3 models in reproducing SAD was assessed by performing EOF analysis of SST monthly low frequency anomalies over the South Atlantic Ocean domain $\left(0^{\circ}-50^{\circ} \mathrm{S} ; 70^{\circ} \mathrm{W}-20^{\circ} \mathrm{E}\right)$. Figure 1 shows the correlation between South Atlantic Ocean SST monthly anomalies and the time coefficient of the first EOF mode
Table 1 Model description: name, country, spatial resolution, and key reference for each model

\begin{tabular}{llll}
\hline Model name & Center country & Resolution Lat $\times$ Lon & Key references \\
\hline CGCM3.1(T63) & Canada & $\sim 2.8 \times 2.8$ & Flato et al. (2000) \\
CSIRO-Mk3.0 & Australia & $\sim 1.9 \times 1.9$ & Gordon et al. (2002) \\
CNRM-CM3 & France & $\sim 2.8 \times 2.8$ & Salas-Mélia et al. (2005) \\
MPI_ECHAM5 & Germany & $\sim 1.9 \times 1.9$ & Roeckner et al. (2003) \\
FGOALS-g1.0 & China & $\sim 2.8 \times 2.8$ & Yu et al. (2004) \\
GFDL-CM2.0 & USA & $2.0 \times 2.5$ & Delworth et al. (2006) \\
GFDL-CM2.1 & USA & $2.0 \times 2.5$ & Delworth et al. (2006) \\
MIROC3.2(hires) & Japan & $\sim 1.125 \times 1.125$ & Hasumi and Emori (2004) \\
MIROC3.2(medres) & Japan & $\sim 2.8 \times 2.8$ & Hasumi and Emori (2004) \\
MRI-CGCM2.3.2 & Japan & $\sim 2.8 \times 2.8$ & Yukimoto et al. (2006) \\
\hline
\end{tabular}


(henceforth SAD) for NCEP-DOE and WCRP-CMIP3 models.

NCEP-DOE (Fig. 1a) shows positive correlations over the tropical South Atlantic, with maximum positive correlation over the eastern tropical and subtropical regions. Negative correlations are observed over the extratropical South Atlantic, with a maximum around $40^{\circ} \mathrm{S}$. This pattern is consistent with the first ocean-atmosphere coupled mode previously observed over the South Atlantic Ocean (Venegas et al. 1997; Sterl and Hazeleger 2003; De Almeida et al. 2007).

In general, the models reproduce the SAD well compared to the observations (Fig. 1), with the exception of FGOALS (Fig. 1f), which represents a single region with significant correlations over the extratropical South Atlantic. GFDL2.0 (Fig. 1g), GFDL2.1 (Fig. 1h), and MIROC-M (Fig. 1j) reproduce the spatial pattern of SAD similar to the observations, with a dipole in SST anomalies between the tropical South Atlantic and extratropical South Atlantic. CNRM (Fig. 1c), CSIRO (Fig. 1d), ECHAM5 (Fig. 1e), and MIROC-H (Fig. 1i) underestimate the regions with negative correlations over the extratropical South Atlantic while CGCMT63 (Fig. 1b) and MRI (Fig. 1k) overestimate the correlations over the eastern extratropical South Atlantic compared to the observations.

The skill of WCRP-CMIP3 models in reproducing observed temporal variability $\mathrm{SAD}$ was evaluated by wavelet analysis of the time-coefficient of SAD (e.g., Torrence and Compo 1998). Although we do not expect to have simultaneous variability in SAD among models and with respect to observations, the wavelet power spectrum analysis allows identification of how the spectral variance of SAD varies over time and therefore provides information about SAD periodicity. Figure 2 shows the SAD time-coefficient and respective wavelet power spectrum for both the NCEP-DOE and WCRP-CMIP3 datasets. The NCEP-DOE (Fig. 2a) indicates high power spectrum variability on scales varying between approximately 60 months (5 years) and 18 months (1.5 year) observed in the mid nineties. Venegas et al. (1996) verified that the South Atlantic first mode of coupled variability is dominated by interdecadal variations of approximately 14-16 years. These oscillations cannot be observed in this analysis due to short period of time considered in this work. De Almeida (2006) observed, however, that this mode also shows significant variability on interannual timescales consistent with the wavelet spectral analysis in Fig. 2a.

SAD simulated by the WCRP-CMIP3 models shows high wavelet spectral density on time-scales longer than
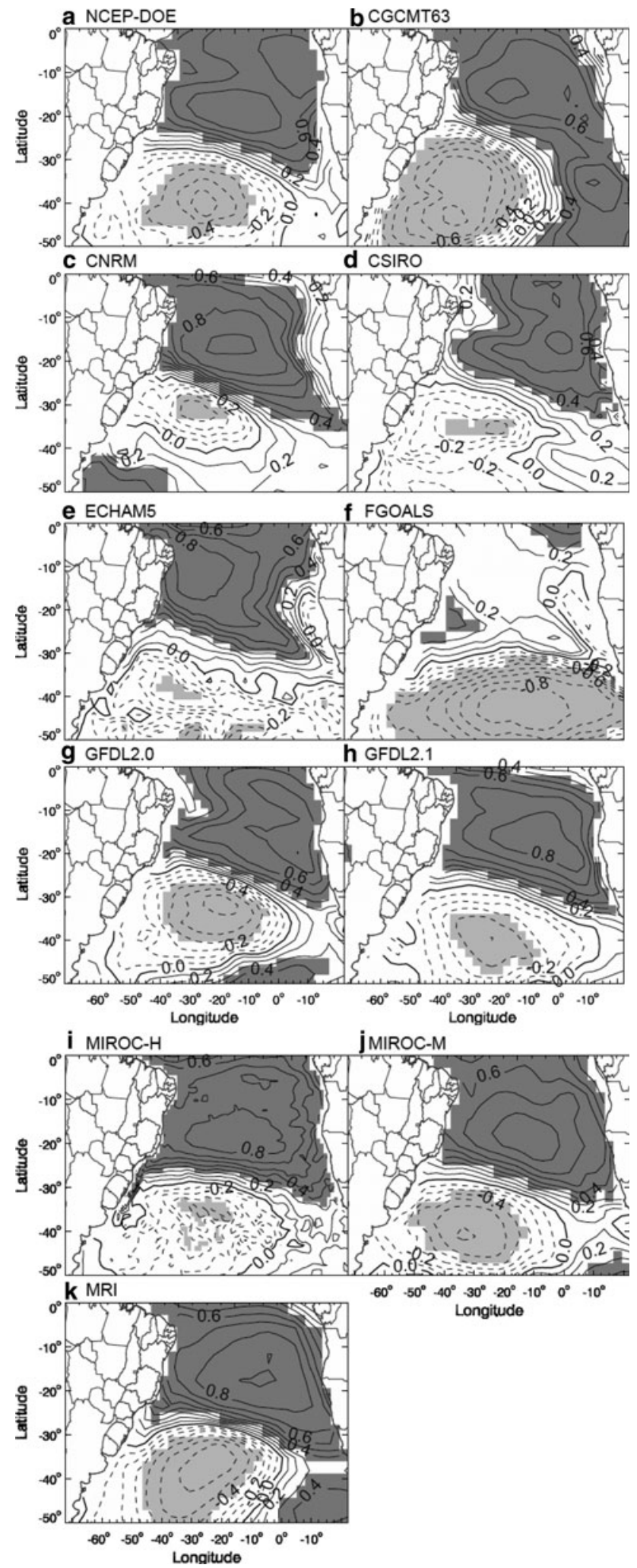

Fig. 1 Correlation between the time coefficient of the first mode of the EOF of SST and SST over the South Atlantic Ocean 


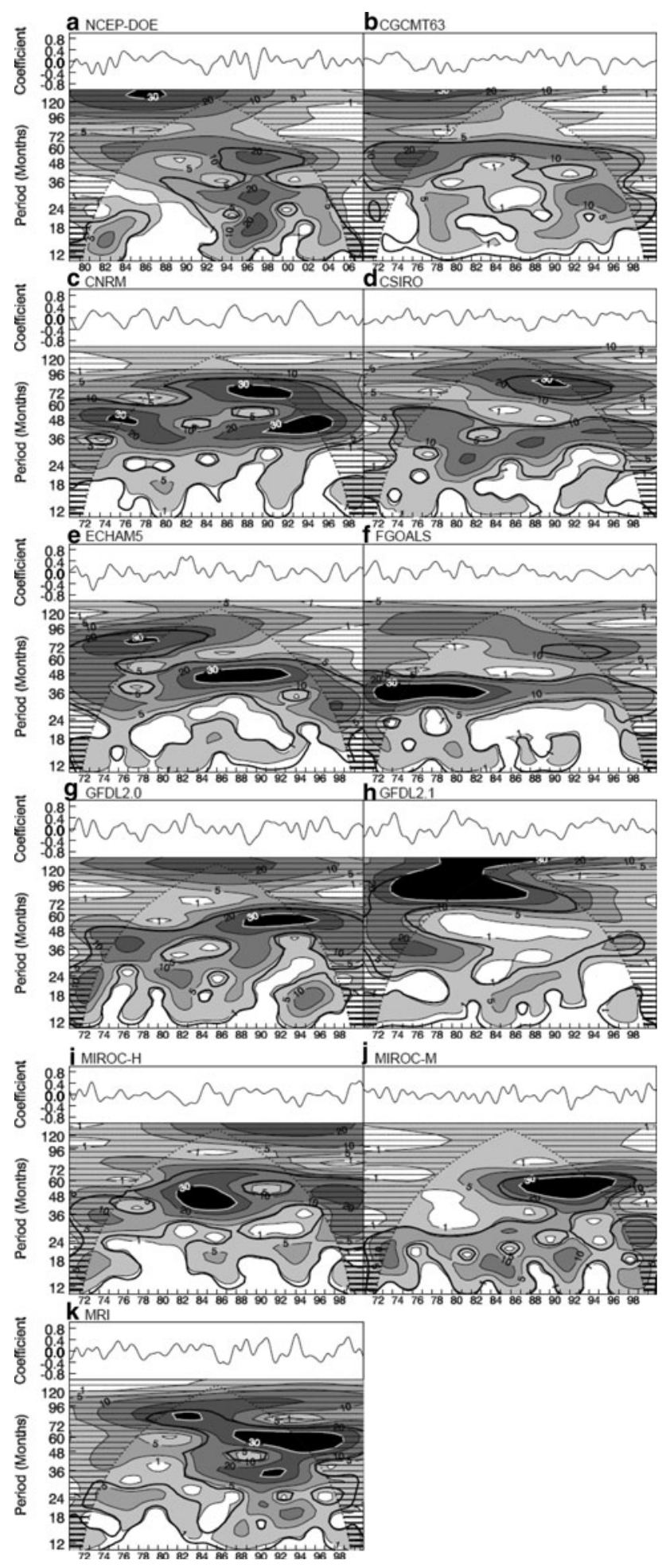

Fig. 2 Wavelet Power Spectrum of the time coefficient of the first mode of the EOF of SST over the South Atlantic Ocean

48 months (4 years). Variations on shorter time scales (1.5-3 years) are also evident in all models (Fig. 2b-k) during the whole period and are relatively more frequent for MIROC-M (Fig. 2j).

\subsection{SAD SST simulated by the WCRP-CMIP3 dataset}

The observed and simulated variations of SST associated with SAD were evaluated by computing the average and standard deviation of SST over the tropical Atlantic region $\left[20^{\circ} \mathrm{S}-10^{\circ} \mathrm{S} ; 40^{\circ} \mathrm{W}-10^{\circ} \mathrm{E}\right]$ during positive (negative) phases of SAD. Warm (Cold) phases were defined when the SAD coefficient was above (below) one (minus one) standard deviation from the mean. Positive (negative) SAD phase is characterized by warm (cold) temperatures in the domain described above.

To test whether the modeled mean SST can be considered distinct from the observed mean SST we applied the test of the difference of the means (Wilks 2006), assuming that the null hypothesis is that the two means can be considered statistically similar at a 5\% significant level. According to this test, only GFDL2.0, MIROC-H and MRI simulate mean SST that cannot be considered distinct with respect to observations for both positive and negative phases (Fig. 3). CNRM and MIROC-M also simulate SST that cannot be considered statistically dissimilar with respect to the observations during SAD negative phase whereas FGOALS realistically reproduces mean SST magnitudes only during SAD positive phase. GFDL2.1 shows higher SST variance in positive phases than in negative phases over the tropical Atlantic, indicating that this model tends to simulate positive phases more intense than negative phases. Observations indicate, however, that SST variances are similar in both phases. CGCMT63 shows the lowest mean SST and variance (Fig. 3) suggesting that this model underestimates the intensity of the phenomenon.

\section{Relationship between SAD and SAMS}

The role of SAD on SAMS onset, demise dates and total monsoonal precipitation was verified by computing the

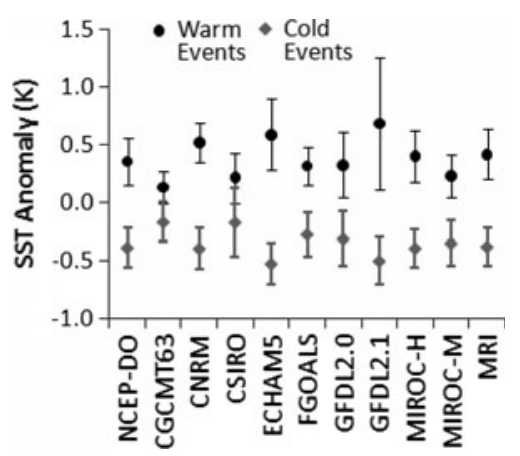

Fig. 3 Mean SST Anomalies during SAD warm and cold events spatially averaged over tropical South Atlantic region $\left[20^{\circ} \mathrm{S}-10^{\circ} \mathrm{S} ;-\right.$ $\left.30^{\circ} \mathrm{W}-10^{\circ} \mathrm{E}\right]$. Bars indicate the standard deviation 
"Sperman Rank Correlation" between the monthly ENSO coefficient and the abovementioned properties of SAMS for each grid point. The Sperman Rank Correlation (hereafter correlation) is simply the Pearson correlation coefficient computed using the ranks of the time series. It is a robust and resistant alternative to the Pearson correlation coefficient, which may underestimate the relationship between two series in the case that their relationship is not strictly linear (Wilks 2006). The statistical significance of the correlations was obtained by the probability table proposed by Zar (1972).

Figure 4 shows the spatial variability of correlation between SAD and SAMS characteristics during the months when they are higher and spatially more coherent. Lagged correlation analysis showed that the relationship between the monthly SAD coefficient and the rainy season characteristics persists for several months (not shown). For simplification the year of the onset will be considered 0 and year of the demise 1. Positive (negative) phases of SAD are associated with late (early) onset of the wet season in a band that extends from Bolivia toward southeastern Brazil and with the early (late) onset of the rainy season over northeastern Brazil (Fig. 4a). Coherent patterns of correlation between SAD and the onset of the rainy season is observed over western and southeastern Brazil from August (0) through December (0) (not shown). In August (0), coherent positive correlations of about 0.4 are observed over Paraguay, western and southeastern Brazil. In the following months positive correlations are observed over Bolivia and in a large region of western Brazil, with correlations of about 0.5 observed in October(0) (Fig. 4a), concomitantly with the median onset dates in that region (Bombardi and Carvalho 2009). Negative correlations are observed over northeastern Brazil persisting from June (0) to October (0) (not shown). These results suggest that SAD phases control physical and dynamical processes that play an important role in the onset of the transition from dry to wet season.

Positive (negative) phases of SAD are related to early (late) demises over southeastern Brazil along with late (early) demises from the Amazon toward northeastern Brazil. Correlations between SAD and demise dates over southeastern Brazil are observed approximately simultaneously with the median end of the rainy season (Bombardi and Carvalho 2009), that is from March (1) to July (1) (not shown). The strongest and most coherent pattern of correlations is observed in May (1) (Fig. 4b). Over northeastern Brazil, correlations are observed from January (0) to May (0) and again from December (0) to July (1). The semiarid northern part of northeastern Brazil experiences its rainy season between February and May (e.g. Uvo et al. 1998).

Patterns of correlation between SAD and accumulated precipitation, duration and demise of the rainy season are very similar. SAD positive (negative) phase is related to the decrease (increase) of the total monsoonal precipitation and a short (long) wet season over southeastern Brazil.
Fig. 4 Rank correlation between a the SAD index of October and Onset, b the SAD index of May and Demise, $\mathbf{c}$ the SAD index of April and accumulated precipitation, $\mathbf{d}$ the SAD index of April and Duration. Contour interval equal 0.1 . Solid lines indicate positive values and dashed lines indicate negative values. Shading shows regions where the rank correlation is statistically significant at $5 \%$ level

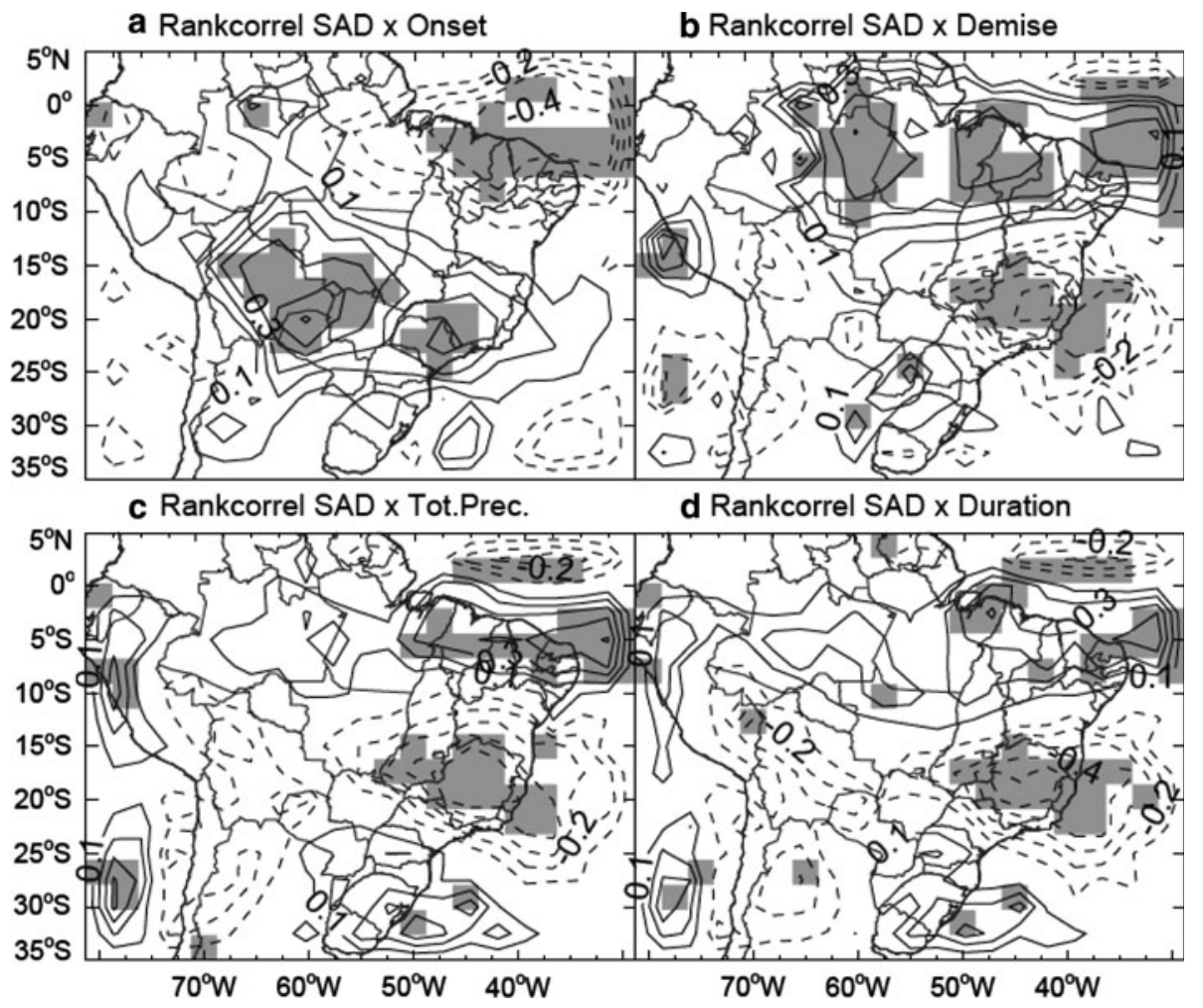


Over northeastern Brazil, SAD positive (negative) phase is related to the increase (decrease) in the total precipitation and long (short) wet seasons. Correlations of same sign are observed over southeastern Brazil from January (1) to July (1) and northeastern Brazil from January (0) to May (1) (not shown).

Variations in the monsoon characteristics have been related to changes in circulation and moisture fluxes (e.g. Zhou and Lau 1998). In this study the relationships between SAD phases and the rainy season were examined by composing low-frequency anomalies of the $850 \mathrm{hPa}$ circulation in each phase of SAD. SAD positive (negative) phase was defined when SAD was above (below) its 75th (25th) percentile which corresponds to warm (cold) SST anomalies over the tropical South Atlantic. Composites where performed during the following periods: median SAMS onset (October (0), Fig. 5a), peak of SAMS (January (1), Fig. 5b), and median SAMS demise (April (1), Fig. 5c) (Bombardi and Carvalho 2009).

SAD negative phase is associated with anomalous easterly flow from the equatorial and southwestern Atlantic toward southeastern and western Brazil in October (0) (Fig. 5a). This anomalous circulation increases moisture transport from the Atlantic toward tropical and equatorial South America, and is related to early onsets of the rainy season over southeastern Brazil, Paraguay and Bolivia east of the Andes (see Fig. 5a). On the other hand, SAD positive phase is related to low-level westerly wind anomalies over southeastern Brazil, which is consistent with the decrease of the transport of moisture from the Atlantic. That seems related to the delay of the onset of the wet season over the region (Fig. 5b).

In January (1), the patterns of circulation anomalies during SAD negative phase (Fig. 5c) are similar to
Fig. 5 Monthly $850 \mathrm{hPa}$ wind low-frequency anomalies composites for both negative (right) and positive (left) phases of SAD on a October, b January and c April. Results are presented only where differences between wind composites during positive and negative phases of SAD are statistically significant at $5 \%$ significance level a SAD (Negative phase) (Oct)

b SAD (Positive phase) (Oct)

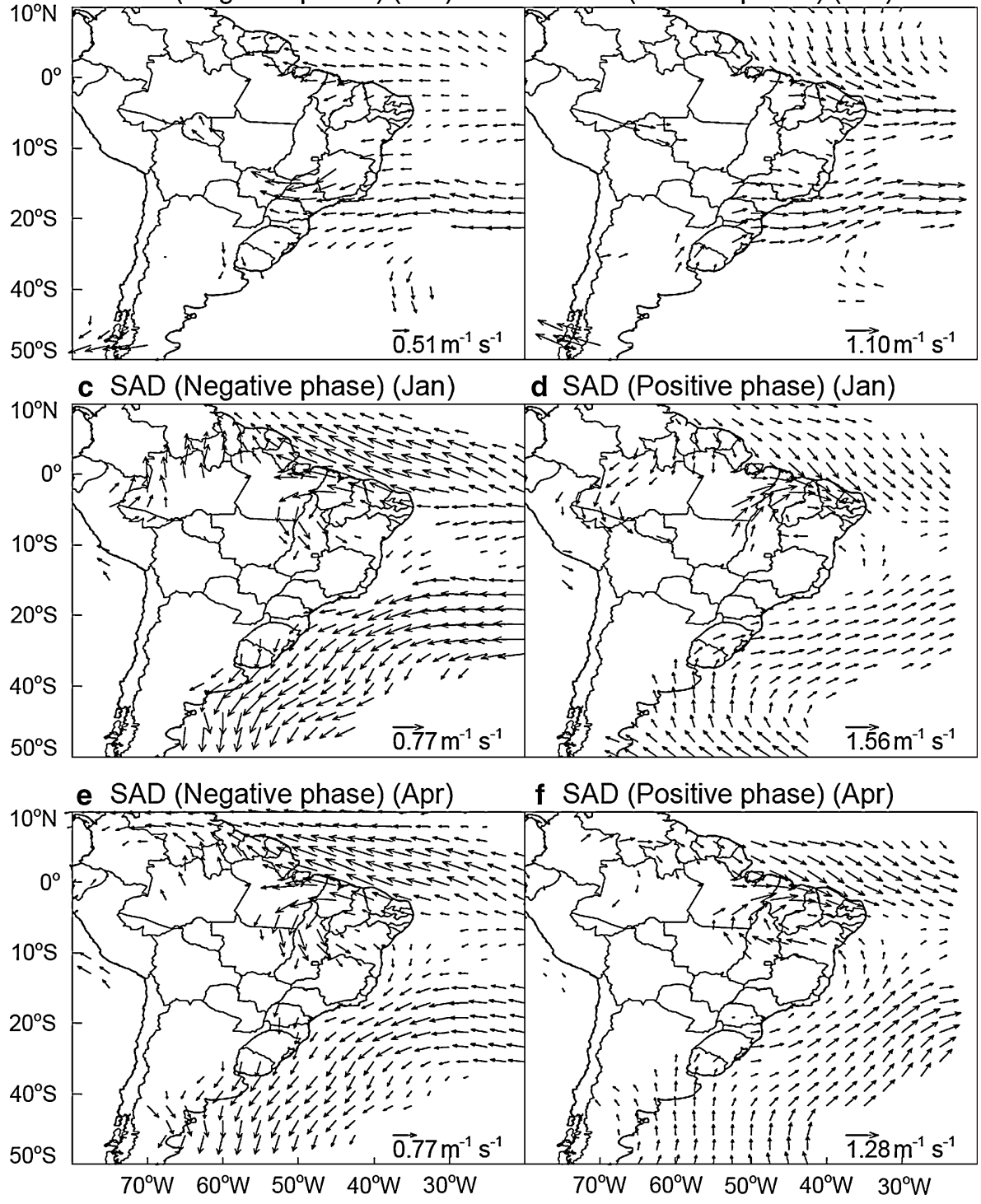


October (0). The intensity of easterly anomalies over the Equatorial Atlantic and subtropical western Atlantic increases and westerly anomalies are observed over central Brazil. These patterns of anomalies suggest an enhancement of the transport of moisture from the eastern Amazon toward southeastern Brazil. This anomalous circulation favors the enhancement of the total seasonal rainfall over southeastern Brazil according to Muza et al. (2009). Opposite anomalous circulations are observed in January during positive SAD phases (Fig. 5d) which is related to the decrease in total precipitation over the same region.

The patterns of anomalous circulation persist until April (1) for negative (Fig. 5e) and positive (Fig. 5f) phases. In summary, negative (positive) SAD phase is related to early (late) onsets, increase (decrease) of monsoonal precipitation, late (early) demises and long (short) durations of the wet season over southeastern Brazil (Fig. 4).

Negative (positive) SST anomalies over the tropical South Atlantic are related to the displacement of the ITCZ northward (southward) of its climatological position causing late (early) onsets, early (late) demises, short (long) duration and a decrease (increase) of total precipitation during the wet season over northeastern Brazil (Fig. 4).Previous studies have shown that dry (wet) years over northeastern Brazil are associated with positive (negative) SST anomalies over tropical North Atlantic and negative (positive) SST anomalies over the tropical South Atlantic (e.g. Hastenrath and Heller 1977; Moura and Shukla 1981; Uvo et al. 1998). Our results are consistent with these previous studies as it indicates that warm SST anomalies over the tropical South Atlantic favor precipitation over northeastern Brazil on interannual timescales. Moreover, Saravanan and Chang (2000) show that the northeast Brazilian rainfall is more strongly correlated with SST anomalies in the southern tropical Atlantic than in the northern tropical Atlantic.

The investigation of the relationships between SAD and the rainy season in the simulations of the WCRP-CMIP3 dataset is shown over three selected regions where the relationships between SAD and the characteristics of the rainy season are strong based on the observations (Fig. 4). The following regions were selected: western Brazil, southeastern Brazil, and northeastern Brazil (Fig. 6a). For all these regions correlation was averaged and the results are shown in Fig. 6b-f.

The observed correlation between SAD and onset of the rainy season over both western and southeastern Brazil increases from January (0) to October (0) and then decreases in the following months. The maximum correlation is observed in October (0) (Fig. 6b, c). No model properly simulates the relationship between $\mathrm{SAD}$ and onset over western Brazil. Over southeastern Brazil only
FGOALS reproduces the phase of the relationship between SAD and the onset. For both western and southeastern Brazil MIROC-H shows similar relationships, however out of phase with respect to observations, with the highest correlation simulated in August (1) (Fig. 6b, c). The relationship between SAD and onset of the rainy season over the northeastern Brazil region is characterized by negative correlations during the year $(0)$ and a large magnitude of the correlations in September (0) and October (0). MIROC-H and CNRM show a similar relationship between SAD and the onset of the rainy season over this region (Fig. 6d).

Over southeastern Brazil, strong negative correlations between SAD and demise are observed from April (1) to September (1). Although CNRM is the only model that simulates the influence of SAD on the demise of the wet season in that region, high correlations are simulated earlier than in the observations (Fig. 6e). On the other hand, over northeastern Brazil CNRM, MIROC-H and MRI reproduce positive correlations similarly to the observations (Fig. 6f), with high values from December (0) to July (1).

Over southeastern Brazil correlations between SAD and accumulated precipitation during the wet season are negative and of higher magnitude between January (1) through July (1). Only CNRM and FGOALS show similar patterns, but the period of highest correlation is early in both models (Fig. 6g). Over northeastern Brazil, high correlation is observed from September (0) to February (1). CNRM, ECHAM5, and MIROC-H reproduce this relationship (Fig. 6h), while CSIRO and FGOALS simulate an opposite pattern of correlations in comparison with observations. The observed seasonal variation of correlation between SAD and the duration of the rainy season and its accumulated precipitation are very similar for both southeastern and northeastern Brazil (Fig. $6 \mathrm{~g}-\mathrm{j}$ ). All models poorly represent the magnitude and phase of these relationships (Fig. 6j).

In summary, WCRP-CMIP3 models simulate the relationship between SAD and the characteristics of the rainy season over northeastern Brazil better than they simulate these relationships over western and southeastern Brazil. One possible reason is that differences in the characteristics of the rainy season over northeastern Brazil are strongly influenced by the position of the ITCZ, which is strongly influenced by external variability (Taschetto and Wainer 2008a, b) and might be better represented by the WCRP-CMIP3. On the other hand, circulation and precipitation variability over western and southeastern Brazil depends on both local and remote forcing (e.g. Marengo et al. 2003; Vera et al. 2006) that may not be properly represented by the WCRP-CMIP3 models investigated here. 
Fig. 6 a Selected regions. Observed and simulated lag rank correlation between monthly SAD index and $\mathbf{b}$ onset over western Brazil; c onset over southeastern Brazil; d onset over northeastern Brazil; e demise over southeastern Brazil; f demise over northeastern Brazil; g accumulated precipitation over southeastern Brazil; $\mathbf{h}$ accumulated precipitation over northeastern Brazil; i duration over southeastern Brazil; j duration over northeastern Brazil. Symbol (0) refers to the months of the year of onset of the wet season and symbol (1) refers to the months of the year of its demise
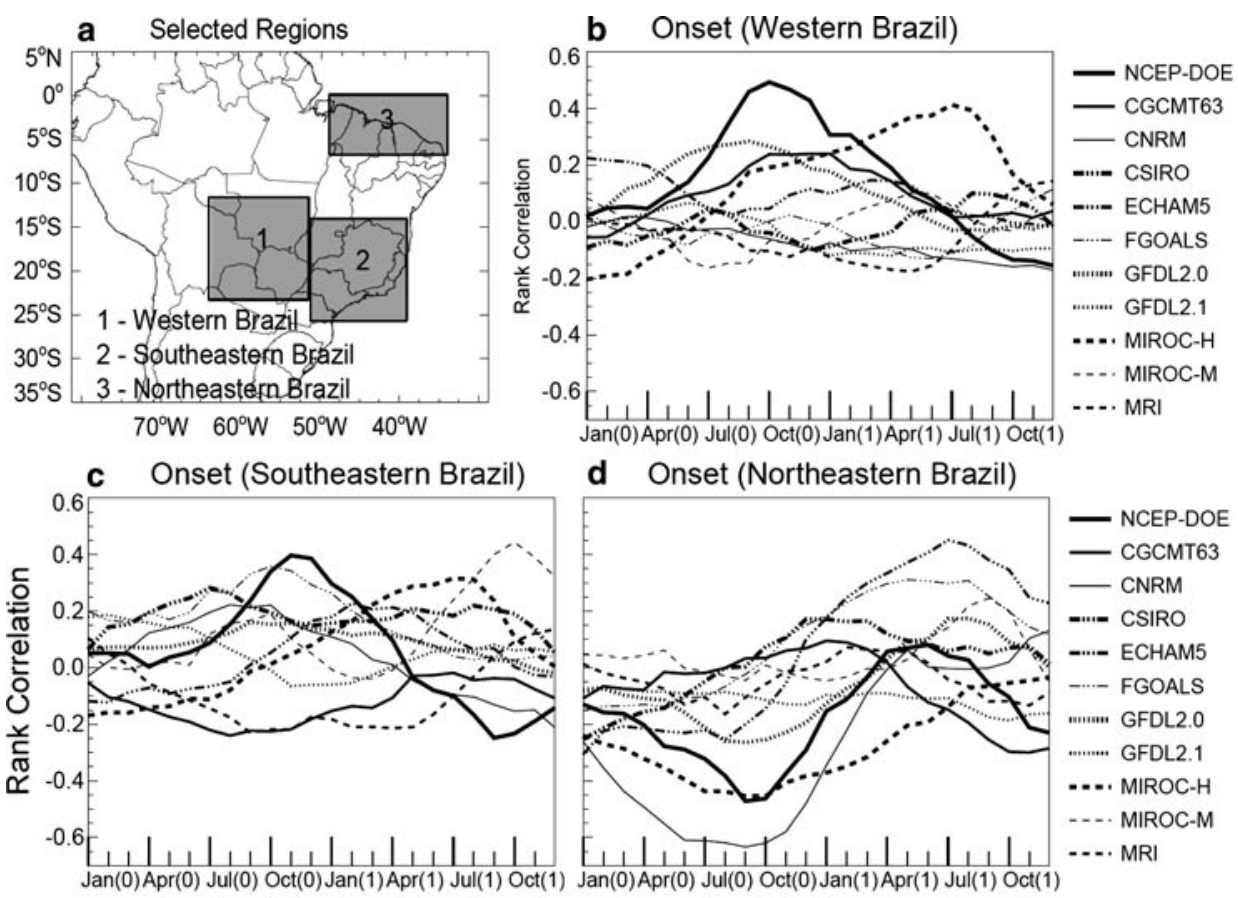

d Onset (Northeastern Brazil)
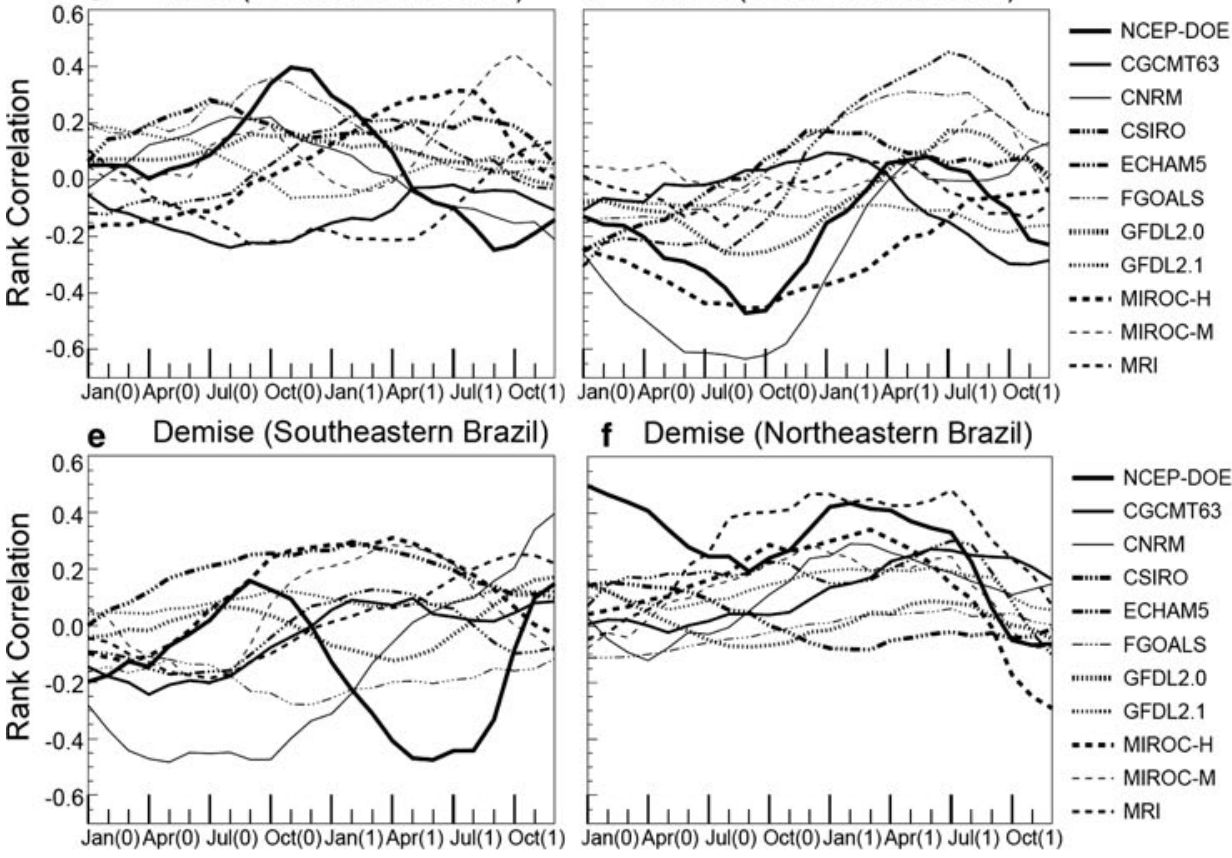

f Demise (Northeastern Brazil)
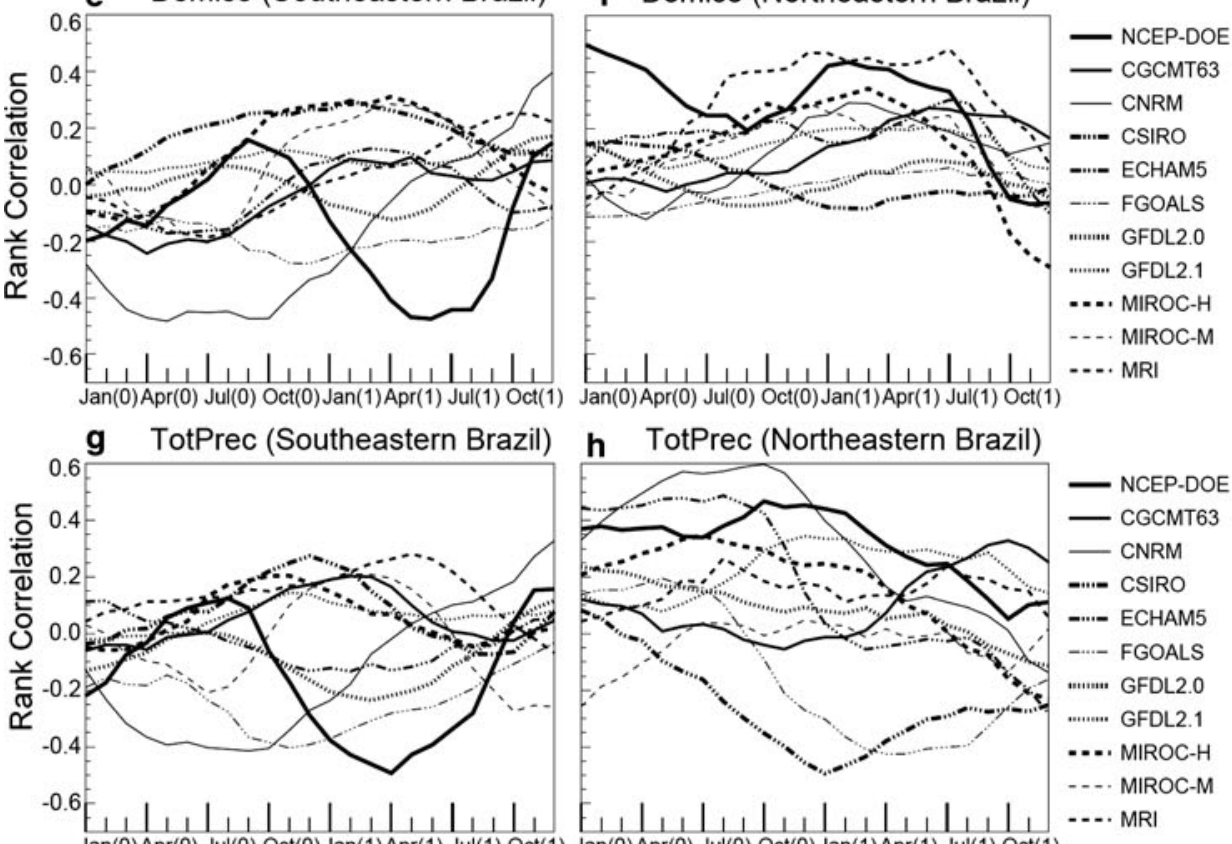

h TotPrec (Northeastern Brazil)
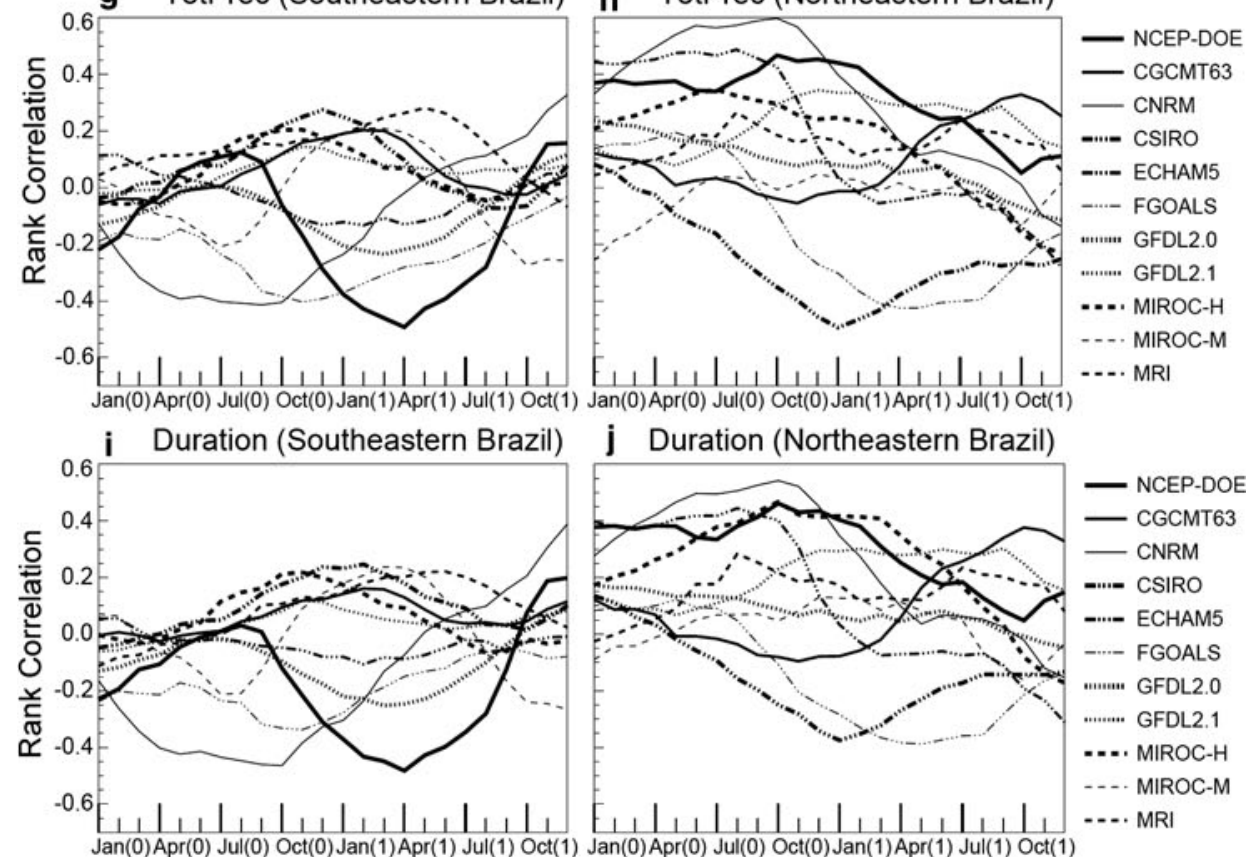

- NCEP-DOE

- CGCMT63

- CNRM

-...- CSIRO

-...- ECHAM5

-...- FGOALS

m..... GFDL2.0

......... GFDL2.1

-... MIROC-H

-... MIROC-M

-... MRI 


\section{ENSO and SAD relationships}

Saravanan and Chang (2000) performed a numerical study of the influence of the Pacific Ocean on the tropical Atlantic Ocean variability and found that ENSO has a significant influence on tropical Atlantic variability. El Niño events are associated with an anomalous Walker circulation, which creates a zonal seesaw pattern in surface pressure. The large-scale subsidence associated with this anomalous Walker circulation explains the negative precipitation anomalies over north-northeastern Brazil and warming of the tropical North Atlantic Ocean.

To verify possible relationships between ENSO and $\mathrm{SAD}$ the former was characterized by performing EOF analysis of SST over the tropical Pacific $\left[30^{\circ} \mathrm{S}-30^{\circ} \mathrm{N}\right.$; $140^{\circ} \mathrm{E}-90^{\circ} \mathrm{W}$ ]. EOF analyses have commonly been used to characterize ENSO phenomena (e.g. Zhou and Lau 2001). The first mode of variability shows spatial patterns consistent with Weare et al. (1976) and Rasmusson and Carpenter (1982) and time variability similar to Kestin et al. (1998) and AchutaRao and Sperber (2002, 2006) (not shown).

The associations between ENSO and SAD were examined by performing cross-correlation analysis (CCA) of the two time coefficients. CCA was calculated for both NCEPDOE and WCRP-CMIP3 datasets (Fig. 7). Statistically significant negative correlations between ENSO and SAD are observed for NCEP-DOE only when SAD leads ENSO by $5-12$ months. No statistically significant correlations were found for ENSO simultaneous to SAD and for ENSO leading SAD. This result suggests that the relationships observed between SAD and the variability of characteristics of the wet season over tropical South America is independent of ENSO phenomenon. Similar relationships

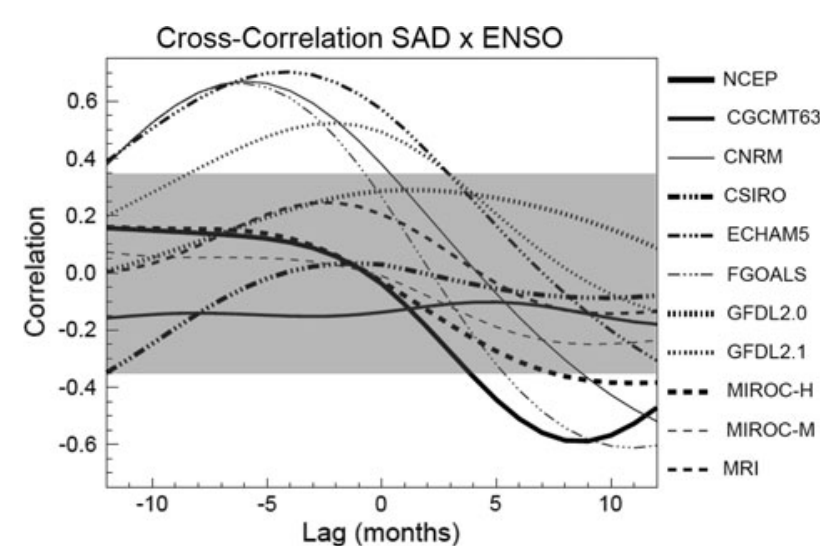

Fig. 7 Lag-correlation between SAD and ENSO time coefficients. Statistically significant correlations at $5 \%$ significance level are observed outside the shaded interval. Negative (positive) lags indicate ENSO leading (lagging) SAD are observed for CNRM, FGOALS, and MIROC-H. Nevertheless, CNRM, ECHAM5, FGOALS, and GFDL2.1 also show high positive correlations when ENSO leads SAD for lags varying between -12 months and +3 months, suggesting that ENSO may be related to SAD variability in these models. ECHAM5 is the model that shows the highest positive correlation ( 0.65$)$ for lag equal -3 months (Fig. 7).

\section{Summary and conclusions}

The present study showed an observational analysis of the influence the South Atlantic Ocean SST on the variability of SAMS characteristics, such as onset and demise dates, accumulated precipitation, and duration. In addition, we examined the ability of ten WCRP-CMIP3 models in reproducing the principal mode of variability of the South Atlantic Ocean and respective relationships with SAMS. In this work every model was examined individually.

It is shown that SAD phases are associated with variations of the rainy season over western and southeastern Brazil. On interannual timescales, positive (negative) SST anomalies over the tropical South Atlantic are associated with late (early) onsets of the wet season over western and southeastern Brazil and early (late) demise, decreased (increased) accumulated precipitation, and short (long) duration of the rainy season over southeastern Brazil. Over northeastern Brazil, positive (negative) SST anomalies over the tropical South Atlantic advance (delay) the onset, delay (advance) the demise, and increase (decrease) the duration and accumulated precipitation during the rainy season. More importantly, we show that the variability of SAD is independent of ENSO phenomenon. These results emphasize the importance of the skill of coupled global models in simulating SAD variability to assess future scenarios of climate change over tropical and subtropical South America.

In general, all models examined in this work can simulate the spatial patterns and temporal variability of SAD. GFDL2.0 and MIROC-M are the models that best represent SAD spatial pattern and frequency and FGOALS does not properly simulate SAD spatial pattern. There is no consistency among simulations of the relationship between SAD and the characteristics of the rainy season over both western and southeastern Brazil.

According to Bombardi and Carvalho (2009) MIROC-H and MRI were considered models with good skill in representing the median characteristics and variability of SAMS. Here we show that the models that best represent SAD spatial and temporal variability are GFDL2.0 and MIROC-M. It is expected that the skill of each model will vary for different measures and the multimodel ensemble 
average is frequently considered the best option (Pierce et al. 2009). However, for dynamical downscaling purposes, in which inputs are required from time to time, the multimodel ensemble is not always the usual procedure. Moreover, a detailed examination of the skills of the WCRP-CMIP3 dataset can provide important insights on the strengths and weaknesses of a particular model and is valuable for researchers and modeling centers.

Acknowledgments We thank Dr. Charles Jones, Dr. Humberto R. Rocha, Dr. José A. Marengo, Dr. Andrea S. Taschetto, and the two anonymous reviewers for their valuable comments and suggestions for this manuscript and the Program for Climate Model Diagnosis and Intercomparison (PCMDI) and the WCRP's Working Group on Coupled Modelling (WGCM) for making available the WCRPCMIP3 multimodel dataset. GPCP data was provided by NOAA and reanalysis by NCEP/NCAR. Authors thank the financial support of the following agencies: R. J. Bombardi CAPES (33002010124P0); L. M. V. Carvalho CNPq (Proc: 482447/2007-9 and 474033/2004-0) and NOAA Office of Global Programs (NOAA NA07OAR4310211). Authors thank the financial support from the European Community's Seventh Framework Programme (FP7/2007-2013) under Grant Agreement $N^{\circ} 212492$ (CLARIS LPB).

Open Access This article is distributed under the terms of the Creative Commons Attribution Noncommercial License which permits any noncommercial use, distribution, and reproduction in any medium, provided the original author(s) and source are credited.

\section{References}

Aceituno P (1988) On the functioning of the Southern Oscillation in the South America sector. Part I: surface climate. Mon Weather Rev 116:505-524

AchutaRao K, Sperber KR (2002) Simulation of the El Niño Southern Oscillation: results from the coupled model intercomparison project. Clim Dyn 19:191-209

AchutaRao K, Sperber KR (2006) ENSO simulation in coupled ocean-atmosphere models: are the current models better? Clim Dyn 19:1-15

Adler RF, Huffman GJ, Chang A et al (2003) The version-2 Global Precipitation Climatology Project (GPCP) monthly precipitation analysis (1979-present). J Hydrometeorol 4:1147-1167

Bombardi RJ, Carvalho LMV (2009) IPCC global coupled climate model simulations of the South America monsoon system. Clim Dyn 33:893-916

Cardoso AO, Silva Dias PL (2004) Atlantic and Pacific variability and temperature during the winter season in São Paulo city. Rev Bras Meteorol 19:307-324 (in Portuguese)

Carvalho LMV, Jones C, Liebmann B (2004) The South Atlantic convergence zone: persistence, intensity, form, extreme precipitation and relationships with intraseasonal activity. J Clim 17:88-108

Coelho CAS, Uvo CB, Ambrizzi T (2002) Exploring the impacts of the tropical Pacific SST on the precipitation patterns over South America during ENSO periods. Theor Appl Climatol 71:185-197

Dai A (2006) Precipitation characteristics in eighteen coupled climate models. J Clim 19:4605-4630

De Almeida (2006) Mechanisms of generation of the South Atlantic dipole and its impacts on climate and oceanic circulation. Dissertation, University of Sao Paulo (in Portuguese)
De Almeida RAF, Nobre P, Haarsma RJ et al (2007) Negative oceanatmosphere feedback in the South Atlantic convergence zone. Geophys Res Lett 34:1-5

Delworth TL, Broccoli AJ, Rosati A et al (2006) GFDLs CM2 global coupled climate models. Part 1: formulation and simulation characteristics. J Clim 19:643-674

Flato GM, Boer GJ, Lee WG et al (2000) The Canadian centre for climate modelling and analysis global coupled model and its climate. Clim Dyn 16:451-467

Ghil M, Mo KC (1991) Intraseasonal oscillations in the global atmosphere. Part II: Southern Hemisphere. J Atmos Sci 48:480 490

Gordon HB, Rotstayn LD, Mcgregor JL et al (2002) The CSIRO Mk3 climate system model. CSIRO Atmospheric Research Tech. Available via DIALOG. http://www.dar.csiro.au/publications/ gordon_2002a.pdf. Accessed 20 Sept 2006

Grimm AM (2003) The El Niño impact on the summer monsoon in Brazil: regional processes versus remote influences. J Clim $16: 263-280$

Grimm AM, Barros VR, Doyle ME (1998) Precipitation anomalies in southern South America associated with El Niño and La Niña events. J Clim 11:2863-2880

Grimm AM, Barros VR, Doyle ME (2000) Climate variability in Southern South America associated with El Niño and La Niña events. J Clim 13:35-58

Grimm AM, Pal JS, Giorgi F (2007) Connection between spring conditions and peak summer monsoon rainfall in South America: role of soil moisture, surface temperature, and topography in Eastern Brazil. J Clim 20:5929-5945

Hastenrath S, Heller L (1977) Dynamics of climate hazards in northeast Brazil. Quart J R Meteorol Soc 103:77-92

Hasumi H, Emori S (2004) K-1 Coupled GCM (MIROC) Available via DIALOG. http://www.ccsr.u-tokyo.ac.jp/kyosei/hasumi/ MIROC/tech-repo.pdf. Accessed 20 Sept 2006

Kanamitsu M, Ebisuzaki W, Woollen JS et al (2002) NCEP-DOE AMIP-II Reanalysis (R-2). Bull Am Meteorol Soc 83:1631-1643

Karoly DJ (1989) Southern Hemisphere circulation features associated with El Nino-Southern Oscillation events. J Clim 2:12391252

Kestin TS, Karoly DJ, Yano J-I (1998) Time-frequency variability of ENSO and stochastic simulations. J Clim 11:2258-2272

Liebmann B, Allured D (2005) Daily precipitation grids for South America. Bull Am Meteorol Soc 86:1567-1570

Liebmann B, Marengo JA (2001) Interannual variability of the rainy season and rainfall in the Brazilian Amazon basin. J Clim $14: 4308-4318$

Magaña V, Ambrizzi T (2005) Dynamics of subtropical vertical motions over the Americas during El Niño boreal winters. Atmos 18:211-235

Marengo JA, Liebmann B, Kousky VE et al (2001) Onset and end of the rainy season in the Brazilian Amazon basin. J Clim 14:833852

Marengo JA, Cavalcanti IFA, Satyamurty P et al (2003) Ensemble simulation of regional rainfall features in the CPTEC/COLA atmospheric GCM. Skill and predictability assessment and applications to climate predictions. Clim Dyn 21:459-475

Mo KC (2000) Relationships between low-frequency variability in the Southern Hemisphere and sea surface temperature anomalies. J Clim 13:3599-3610

Moura AD, Shukla J (1981) On the dynamics of droughts in northeast Brazil: observation, theory, and numerical experiments with a general circulation model. J Atmos Sci 38:2653-2675

Muza MN, Carvalho LMV (2006) Intraseasonal and interannual variability of extreme precipitation and drought over southern Amazon during the Austral summer. Rev Bras Meteorol 21:2941 (in Portuguese) 
Muza MN, Carvalho LMV, Jones C et al (2009) Intraseasonal and interannual variability of extreme dry and wet events over Southeastern South America and Subtropical Atlantic during the Austral summer. J Clim 22:1682-1699

Paegle JN, Mo KC (2002) Linkages between summer rainfall variability over South America and sea surface temperature anomalies. J Clim 15:1389-1407

Pierce DW, Barnett TP, Santer BD et al (2009) Selecting global climate models for regional climate change studies. PNAS 106:8441-8446

Rasmusson EM, Carpenter TH (1982) Variation in Tropical Sea surface temperature and surface wind fields associated with the Southern Oscillation/El Niño. Mon Weather Rev 110:354-384

Robertson AW, Mechoso CR (2000) Interannual and interdecadal variability of the South Atlantic convergence zone. Mon Weather Rev 128:2947-2957

Roeckner E, Bäuml G, Bonaventura L et al (2003) The atmospheric general circulation model ECHAM5. Part 1: Available via DIALOG. http://www.mpimet.mpg.de/fileadmin/publikationen/ Reports/max_scirep_349.pdf Accessed 8 Jan 2008

Ropelewski CF, Halpert MS (1987) Global and regional scale precipitation associated with the El Niño/Southern Oscillation. Mon Weather Rev 115:1606-1626

Salas-Mélia D, Chauvin F, Déqué M et al (2005) Description and validation of the CNRM-CM3 global coupled model. Available via DIALOG. http://www.cnrm.meteo.fr/scenario2004/paper_ cm3.pdf. Accessed 8 Jan 2008

Saravanan R, Chang P (2000) Interaction between Tropical Atlantic variability and El Niño-Southern Oscillation. J Clim 13:21772194

Sterl A, Hazeleger W (2003) Coupled variability and air-sea interaction in the South Atlantic Ocean. Clim Dyn 21:559-571

Taschetto AS, Wainer I (2008a) The impact of subtropical South Atlantic SST on South American precipitation. Ann Geophys 26:3457-3476

Taschetto AS, Wainer I (2008b) Reproducibility of South American precipitation due to Subtropical South Atlantic SSTs. J Clim 21:2835-2851
Torrence C, Compo GP (1998) A practical guide to wavelet analysis. Bull Am Meteorol Soc 79:61-78

Uvo CB, Repelli CA, Zebiak SE et al (1998) The relationships between Tropical Pacific and Atlantic SST and Northeast Brazil monthly precipitation. J Clim 11:551-562

Venegas SA, Mysak LA, Straub DN (1996) Evidence for interannual and interdecadal climate variability in the South Atlantic. Geophys Res Lett 23:2673-2676

Venegas SA, Mysak LA, Straub DN (1997) Atmosphere-ocean coupled variability in the South Atlantic. J Clim 10:2904-2920

Vera C, Silvestre G (2009) Precipitation interannual variability in South America from the WCRP-CMIP3 multi-model dataset. Clim Dyn 32:1003-1014

Vera C, Higgins W, Ambrizzi T et al (2006) Toward a unified view of the American monsoon systems. J Clim 19:4977-5000

Weare BC, Navato AR, Newell RE (1976) Empirical orthogonal analysis of Pacific Sea surface temperatures. J Phys Oceanogr 6:671-678

Wilks DS (2006) Statistical methods in the atmospheric sciences. Academic Press, New York

Xie P, Janowiak JE, Arkin PA et al (2003) GPCP pentad precipitation analyses: an experimental dataset based on gauge observations and satellite estimates. J Clim 16:2197-2214

Yu Y, Zhang X, Guo Y (2004) Global coupled ocean atmosphere general circulation models in LASG/IAP. Adv Atmos Sci 21:444-455

Yukimoto S, Noda A, Kitoh A et al (2006) Present-day climate and climate sensitivity in the Meteorological Research Institute Coupled GCM, Version 2.3 (MRI-CGCM2.3). J Meteorol Soc Jpn 84:333-363

Zar JH (1972) Significance testing of the Spearman rank correlation coefficient. J Am Stat Assoc 67:578-580

Zhou J, Lau KM (1998) Does a monsoon climate exist over South America? J Clim 11:1020-1040

Zhou J, Lau KM (2001) Principal modes of interannual and decadal variability of summer rainfall over South America. Int J Climatol 21:1623-1644 